\title{
An Improved Linear Programming Approach for Simultaneous Optimization of Water and Energy
}

\author{
Maziar Kermani ${ }^{\mathrm{b}, *}$, Zoé Périn-Levasseur ${ }^{\mathrm{b}}$, Marzouk Benalib ${ }^{\mathrm{b}}$, Luciana Savulescu ${ }^{\mathrm{b}}$, \\ Francois Maréchal ${ }^{\mathrm{a}}$ \\ ${ }^{a}$ EPFL/Industrial Processes \& Energy Systems Engineering Group (IPESE), Lausanne, \\ Switzerland \\ ${ }^{b}$ Natural Resources Canada/CanmetENERGY, Varennes, Quebec, Canada \\ maziar.kermani@epfl.ch
}

\begin{abstract}
An optimization method based on Mixed Integer Linear Programming (MILP) has been developed for simultaneous optimization of water and energy (SOWE) in industrial processes. The superstructure integrates process thermal streams and optimizes the consumption of water while maximizing internal heat recovery to reduce thermal utility consumption. In this paper, additional concepts have been implemented in the superstructure to target the issues of the pulp and paper processes. Non-Isothermal Mixing (NIM) has been considered at different locations in order to reduce the number of thermal streams and decrease the investment cost by avoiding unnecessary investment on heat exchangers. The concepts of restricted matches and water tanks have been added to the superstructure to adapt it to the pulp and paper case studies. The Integer-Cut Constraint (ICC) technique has been combined with the MILP model to generate systematically a set of optimal solutions to support the decision-making for cost-effective configurations.
\end{abstract}

Keywords: combined water and energy; process integration; linear programming.

\section{Introduction}

Improving the energy efficiency of pulp and paper mills is strongly interconnected to the optimal management of water, which underlines the development of a methodology that can address water and energy reduction simultaneously. Reported state-of-the-art publications on water and energy optimization can be categorized into two groups: conceptual and mathematical methods. Conceptual methods are generally insight-based approaches such as Savulescu and Alva-Argaez (2013). They provide a good vision of the whole procedure using powerful visualization tools. However, these approaches may result in an arduous path to reach the minimum water and energy consumption. On the other side, non-linear mathematical approaches such as Ahmetovic and Kravanja (2014) are complex and less popular among experienced engineers due to their difficult applications in practical contexts. These methods cannot guarantee the global optimum. A further barrier when developing a combined water-energy optimization is the unavailability of measured water contamination levels, which makes it difficult to target water reuse opportunities. This paper provides a novel simultaneous optimization of water and energy (SOWE) method built on a MILP model overcoming these barriers. The NIM concept and multi-contaminant problem as well as the simultaneous integration of the water network and process energy streams have also been addressed by linear programming. 


\section{Methodology}

\subsection{SOWE superstructure definition}

The SOWE method is based on a mathematical formulation of the superstructure optimization, including a heat cascade and a source/sink model. A set of water sources $\mathrm{N}_{\mathrm{S}}$ and demands $\mathrm{N}_{\mathrm{D}}$ are available. Each source produces a specific amount of water $\dot{\mathrm{m}}_{\mathrm{S}}$ at a given temperature $T_{S}$ with a maximum allowed contamination level(s) $C_{S}^{\max }$. Each demand needs an amount of water $\dot{m}_{D}$ with a specific temperature $\mathrm{T}_{\mathrm{D}}$ and maximum level(s) of contamination $C_{D}^{\max }$. Besides, a list of process thermal streams $\mathrm{N}_{\text {th }}$ is also provided consisting of hot and cold streams. Each stream is characterized by an inlet (outlet) temperature, $\mathrm{T}_{\text {in }}\left(\mathrm{T}_{\text {out }}\right)$ together with a heat load $\mathrm{Q}_{\text {th }}$. Thermal utilities (i.e. hot or cold utilities) are also available in case that energy within the system is not sufficient to satisfy the energy demands. The existing wastewater treatment system processes wastewater at a fixed temperature and any contamination level. Figure 1 illustrates the SOWE superstructure with two sources and two demands. All sources-demands interconnections are considered as well as the NIM concept. Since SOWE is based on MILP, an innovative linearized formulation of the NIM has been integrated in the superstructure. This is done by replacing unknown temperature levels at which NIM can take place with pre-defined levels through the concept of sub-units. These temperature levels are the ones available in the water network.

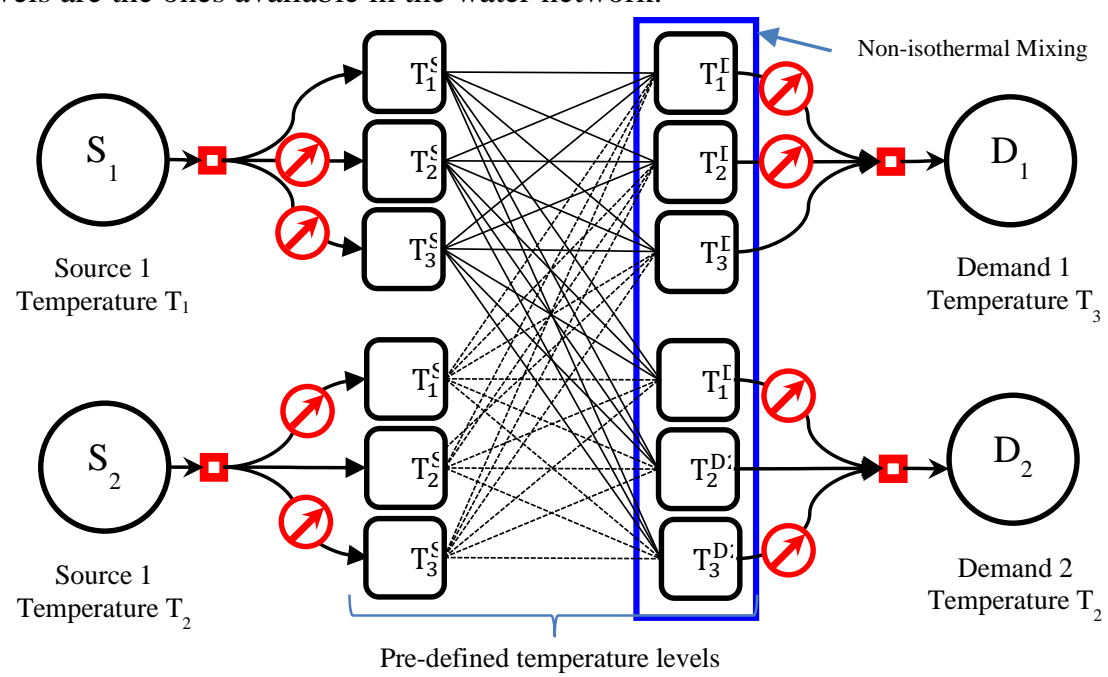

Figure 1. Linear SOWE superstructure for 2 sources, 2 demands, and 3 levels of temperature.

\subsection{Mathematical formulation}

The objective function of the MILP corresponds to minimizing the total cost:

$\min _{R_{r}, y_{w}, f_{w}}\left(\sum_{w=1}^{N_{w}} c_{w} \times f_{w}\right) \times t i m e+\frac{i(1+i)^{n_{y}}}{(1+i)^{n_{y}}-1} \sum_{w=1}^{n_{w}}\left(I C F_{w} \times y_{w}+I C P_{w} \times f_{w}\right)$

Subjected to:

1. Existence of a system (e.g. utility of fresh water, sub-units, hot utility ...): 
$y_{w} f_{w}^{\min } \leq f_{w} \leq y_{w} f_{w}^{\max } \quad y_{w} \in\{0,1\}, \forall w=1, \ldots, N_{w}$

2. Heat cascade model (Maréchal and Kalitventzeff, 1996)

3. Source/Sink model,

4. Temperature constraint on mixers before water demands: The weighted average temperature of all inlet mass streams $i$ to demand $j$ should be equal to its temperature multiplied by its mass flow rate. This is the non-isothermal constraint at the inlet of each mixer.

$\sum_{i=1}^{N_{\text {sub-units }}} T_{i} \times f_{i, j}=T_{j} \times f_{j} \quad \forall j=1, \ldots, N_{D}$

5. Contamination constraint on mixers before water demands: A concentration of total suspended solids measured in ppm is selected as the water contaminant. The weighted average of the contamination level of all mass streams inlet to the demand should be equal or less than the maximum allowed contamination demand. For multi-contaminant problems, Yang and Grossmann (2013) proved that the minimum fresh water target by Eq. (4) is the same as the optimum predicted value by nonlinear formulation under a specific condition, i.e. at least one contamination reaches its maximum level at all the process units with nonzero water reuse streams.

$\sum_{i=1}^{N_{\text {sub-units }}} C_{i, \max } \times f_{i, j} \leq C_{j, \max } \times f_{j}$

With:

$R_{r} \quad$ the heat cascaded from the temperature interval $\mathrm{r}$ to the lower temperature intervals

$\begin{array}{ll}C_{i}^{\max } & \left(\mathrm{r}=1, \mathrm{n}_{\mathrm{r}}+1\right)[\mathrm{kW}] \\ \text { maximum contamination level allowed }\end{array}$

$c_{w} \quad$ operating cost of utility $w,[\mathrm{USD} / \mathrm{s} /$ unit of w]

$f_{w} \quad$ level of utilization of subsystem w (e.g. the heat load of a thermal utility unit)

time operating time $[s]$

$i \quad$ interest rate

$I C F_{w} \quad$ fixed investment cost $[\mathrm{USD} / \mathrm{y}]$

$I C P_{w} \quad$ proportional investment cost [USD/y/unit of w]

$f_{i, j} \quad$ mass transfer from unit $\mathrm{i}$ to unit $\mathrm{j}[\mathrm{kg} / \mathrm{s}]$

\section{Benchmarking analysis}

The improved MILP-based SOWE approach has been evaluated using several examples from the literature (Bagajewicz et al. (2002), and Dong et al. (2008)). The benchmarking analysis was done using key performance indicators based on energy and water targets, network complexity, and operating and investment costs.

3.1. Addressing a multi-contaminant problem

Dong et al. (2008) example is a multi-contaminant problem solved via a MINLP algorithm. Fresh water $(0 \mathrm{ppm})$ is available at $80{ }^{\circ} \mathrm{C}$. Hot and cold utilities are steam at $160{ }^{\circ} \mathrm{C}$, and cooling water at $10^{\circ} \mathrm{C}$.

As shown in Table 1, SOWE methodology reaches the same targets as Dong's approach, which indicates a correct formulation of multi-contaminant problem with linear programming. Moreover, it shows that the new linear formulation of NIM allows 
reducing the investment cost by almost $10 \%$. This can be explained by the selected streams lowering the surface area of heat exchangers.

\subsection{Comparing two MILP approaches}

In Bagajewicz et al. (2002) example, the MILP approach relies on two sequential LP problems to target the water and energy consumptions. A MILP transshipment model is used to build the HEN having the utility targets as constraints.

Bagajewicz et al. (2002) only consider heat exchange among fresh water and wastewater streams while SOWE method includes water reuse streams in the heat exchange network.

Table 1. Performance, complexity and economic indicators

\begin{tabular}{|c|c|c|c|c|c|}
\hline \multirow{2}{*}{\multicolumn{2}{|c|}{ Related Article }} & \multicolumn{2}{|c|}{ Example of Dong } & \multicolumn{2}{|c|}{ Example of Bagajewicz } \\
\hline & & $\begin{array}{c}\text { Dong et al. } \\
2008\end{array}$ & SOWE & $\begin{array}{l}\text { Bagajewicz et } \\
\text { al. } 2002\end{array}$ & SOWE \\
\hline $\begin{array}{r}\text { Ap } \\
\text { Mathematical prograr } \\
\text { Objective/Objective fu } \\
\text { HEN }\end{array}$ & $\begin{array}{l}\text { roach } \\
\text { Iming } \\
\text { action } \\
\text { esign }\end{array}$ & $\begin{array}{l}\text { Mathematical } \\
\text { MINLP } \\
\text { Total cost } \\
\text { YES }\end{array}$ & $\begin{array}{l}\text { MILP } \\
\text { Total cost } \\
\text { NO }\end{array}$ & $\begin{array}{l}\text { Mathematical } \\
\text { MILP } \\
\text { Nb. of matches } \\
\text { YES }\end{array}$ & $\begin{array}{l}\text { MILP } \\
\text { Total cost } \\
\text { NO }\end{array}$ \\
\hline \multicolumn{6}{|c|}{ Key Performance Indicators (KPIs) } \\
\hline $\begin{array}{r}\text { Vapor } \\
\text { Cooling water } \\
\text { Clean water } \\
\text { Contaminated water } \\
\end{array}$ & $\begin{array}{l}\mathrm{kW} \\
\mathrm{kW} \\
\mathrm{kg} / \mathrm{s} \\
\mathrm{kg} / \mathrm{s}\end{array}$ & $\begin{array}{c}1254 \\
7106 \\
70 \\
70 \\
\end{array}$ & $\begin{array}{c}1254 \\
7106 \\
70 \\
70 \\
\end{array}$ & $\begin{array}{c}5265 \\
0 \\
126 \\
126 \\
\end{array}$ & $\begin{array}{c}5265 \\
0 \\
126 \\
126 \\
\end{array}$ \\
\hline \multicolumn{6}{|l|}{ Network Indicators } \\
\hline $\begin{array}{r}\text { Nb. of thermal streams } \\
\text { Heat exchangers } \\
\text { Total area of HEs } \\
\text { Nb. of mixers (NIM) }\end{array}$ & $\begin{array}{c}- \\
- \\
m^{2} \\
-\end{array}$ & $\begin{array}{c}7 \\
6 \\
181 \\
4(2) \\
\end{array}$ & $\begin{array}{c}6 \\
6 \\
114 \\
6(3) \\
\end{array}$ & $\begin{array}{c}10 \\
12 \\
788 \\
13(10) \\
\end{array}$ & $\begin{array}{c}8 \\
7 \\
760 \\
21(12) \\
\end{array}$ \\
\hline \multicolumn{6}{|l|}{ Financial Indicators } \\
\hline $\begin{array}{r}\text { Operating cost } \\
\text { Investment cost } \\
\text { Total cost }\end{array}$ & $\begin{array}{l}\$ / y r \\
\$ / y r \\
\$ / y r\end{array}$ & $\begin{array}{c}1,157,518 \\
82,015 \\
1,239,533\end{array}$ & $\begin{array}{c}1,157,518 \\
74,355 \\
1,231,873\end{array}$ & $\begin{array}{c}1,349,553 \\
196,289 \\
1,545,841\end{array}$ & $\begin{array}{c}1,349,553 \\
129,828 \\
1,479,381\end{array}$ \\
\hline
\end{tabular}

The results indicate that the number of thermal streams is reduced by $20 \%$ due to the higher number of NIMs (12 compared to 10).

\section{SOWE adjustment for pulp and paper industry}

The concept of restricted matches between process unit operations (PUOs) aims to:

1. Address economic and process topology limitations; i.e. recycling between specific processes or a heat exchange among certain streams can be beneficial or disadvantageous depending on economic, material and geographical constraints.

2. Avoid the use of contamination levels, which are often difficult to have access in the pulp and paper processes.

A level of restriction is defined for each stream using binary variables. Eq.(5) allows or prevents connections among PUOs: 
$\sum_{i=1}^{N_{\text {sub-units }}} R M^{k}{ }_{i} \times f_{i, j} \geq R M_{j}^{k} \times f_{j}$

Water tanks have also been added to the superstructure to assess their temperature variation influence on utility consumption. They act as hubs in which water streams from outlet of heat exchangers can be mixed non-isothermally to reach a fixed temperature and then can be used in any other process units or cooling duties. In a real industrial process, water streams and process thermal streams are often combined, i.e. process thermal streams can interact with water thermal streams for energy target reduction. SOWE method has the ability to address this aspect, which has never been addressed explicitly in the literature. ICC can also be used to generate automatically the ordered set of solutions (Fazlollahi et al., 2012). This allows comparing the solutions with regard to different criteria, which has not been taken into account in the objective function. These SOWE features are applied to a pulp and paper case study.

\subsection{Pulp and paper case study}

SOWE method has been applied to a simplified kraft pulp process. The water system and the main thermal process streams from which heat can be recovered are shown in Table 2. Fresh water is considered as process and cooling water resulting in simultaneous minimization of water and energy consumptions.

Table 2. Operating data and conditions of the kraft process case study.

\begin{tabular}{lccclcccc}
\hline \multirow{2}{*}{ PUOs } & $\mathbf{T}_{\text {in }}$ & $\mathbf{T}_{\text {out }}$ & $\mathbf{F l o w}$ & \multirow{2}{*}{ Process thermal streams } & $\mathbf{T}_{\text {in }}$ & $\mathbf{T}_{\text {out }}$ & Load \\
\cline { 2 - 4 } \cline { 7 - 9 } & ${ }^{\circ} \mathrm{C}$ & ${ }^{\circ} \mathrm{C}$ & $\mathrm{kg} / \mathrm{s}$ & & ${ }^{\circ} \mathrm{C}$ & ${ }^{\circ} \mathrm{C}$ & $\mathrm{kW}$ \\
\hline Pulp machine & 50 & 50 & 10 & Surface condenser & 65 & 64 & 7,560 \\
Bleaching & 70 & 70 & 20 & Turpentine condenser & 95 & 50 & 10,920 \\
Washing & 65 & 65 & 35 & Effluent & 75 & 40 & 2,205 \\
Stock preparation & 62 & 62 & 25 & Dryer exhaust & 59 & 30 & 1,050 \\
Recausticization & 35 & 35 & 20 & Contaminated condensate & 80 & 65 & 630 \\
\hline Source and sink & & & & Utility thermal streams & & & \\
\hline Fresh water & - & 10 & - & Hot utility & 120 & 120 & - \\
Waste water & - & 30 & - & Cold utility & 10 & 35 & - \\
\hline Water tanks & & & & 35 & 35 & - \\
\hline Hot water tank & 62 & 62 & - & Warm water tank & 35 & \\
\hline
\end{tabular}

Restricted matches concept is applied using the following restrictions:

1. Outlet of recausticizing, washing and bleaching cannot be reused.

2. Outlet of the pulp machine can only be reused in washing section.

3 . Outlet of the stock preparation can only be reused in bleaching section.

4. No fresh water can be used to dilute the wastewater streams,

5. No recycling can take place within each tank.

6. A connection is possible from cold water tank to warm water tank either directly or through a heat exchanger.

The use of binary variables to allow or prevent a match is used in the superstructure model.

Table 3 shows that by using SOWE method the total water consumption will be reduced by $17 \%$ while no thermal hot utility is used. The investment cost is increased by $10 \%$ 
due to a lower approach temperature in heat exchangers. Though total cost decreases by $60 \%$. When compared to the actual operating condition of the total kraft mill, this corresponds to a $5 \%$-reduction of the total cost. Sensitivity analysis can also be performed on tank temperature to investigate its impact on utility consumption.

Table 3. Results of the case study

\begin{tabular}{|c|c|c|c|c|}
\hline & & & Reference Case & SOWE \\
\hline \multirow{5}{*}{$\begin{array}{c}\text { Key } \\
\text { Performance } \\
\text { Indicators }\end{array}$} & Fresh water & $\mathrm{kg} / \mathrm{s}$ & 137 & $104(-24 \%)$ \\
\hline & Hot utility & $\mathrm{kW}$ & 3,392 & 0 \\
\hline & Cold utility* & $\mathrm{kW}(\mathrm{kg} / \mathrm{s})$ & $14,257(136)$ & $12,795(122)$ \\
\hline & Total water consumption ${ }^{1}$ & $\mathrm{~kg} / \mathrm{s}$ & 273 & $227(-17 \%)$ \\
\hline & Waste outlet temperature & ${ }^{\circ} \mathrm{C}$ & 59 & 59 \\
\hline \multirow{3}{*}{$\begin{array}{l}\text { Network } \\
\text { Indicators }\end{array}$} & $\mathrm{Nb}$ of thermal streams & - & 13 & 8 \\
\hline & $\mathrm{Nb}$ of heat exchangers & - & 7 & 7 \\
\hline & Total area of HEs & $\mathrm{m}^{2}$ & 310 & 462.6 \\
\hline \multirow{3}{*}{$\begin{array}{l}\text { Financial } \\
\text { Indicators }\end{array}$} & Operating cost & $\$ / y r$ & 774,635 & $243,645(-69 \%)$ \\
\hline & Investment cost & $\$ / y r$ & 104,287 & $114,673(+10 \%)$ \\
\hline & Total cost & $\$ / y r$ & 878,922 & $358,318(-60 \%)$ \\
\hline
\end{tabular}

* Cold utility required to cool down waste streams to $30^{\circ} \mathrm{C}$.

${ }^{1}$ Sum of fresh water and water needed to cool down the waste.

\section{Concluding remarks}

A linear modified definition of non-isothermal mixing has been included in a linear mathematical model for simultaneous optimization of water and energy to reduce the number of thermal streams in the network. Hence, it reduces the number of heat exchangers and decreases the investment cost. To respond to the pulp and paper industry needs, the SOWE method was improved by including the concepts of restricted matches, temperature flexibility of water tanks, and integer-cut constraint technique. As a result, a spectrum of cost-effective decision-making solutions is obtained. The MILP/ICC-based SOWE method has been satisfactorily applied to a kraft mill resulting in a complete elimination of the steam used for hot water production through water reuse, equivalent in lowering water intake by $24 \%$.

\section{References}

E. Ahmetovic, Z. Kravanja, 2014, Simultaneous optimization of heat-integrated water networks involving process-to-process streams for heat integration, Applied Thermal Engineering, 62, 302-317.

M. Bagajewicz, H. Rodera, M. Savelski, 2002, Energy efficient water utilization systems in process plants, Computers and Chemical Engineering, 26, 59-79.

H.-G. Dong, C.-Y. Lin, C.-Y. Chang, 2008, Simultaneous optimization approach for integrated water-allocation and heat-exchange network, Chemical Engineering Science, 63, 3664-3678.

S. Fazlollahi, P. Mandel, G. Becker, F. Maréchal, 2012, Methods for multi-objective investment and operating optimization of complex energy systems, Energy, 45, 12-22.

F. Maréchal, B. Kalitventzeff, 1996, Targeting the minimum cost of energy requirement: A new graphical technique for evaluating the integration of utility systems, Computers and Chemical Engineering, 20, S225-S230.

L. Savulescu, A. Alva-Argaez, 2013, Process Integration Concepts for Combined Energy and Water Integration, In J. J. Klemeš (Ed.), Handbook of Process Integration (PI): Minimisation of Energy and Water Use, Waste and Emissions (pp. 461-483), Woodhead Publishing Limited, Cambridge, UK. DOI: 10.1533/9780857097255.4.461

L. Yang, I. E. Grossmann, 2013, Water targeting Models for Simultaneous Flowsheet Optimization, Industrial and Engineering Chemistry Research, 52, 3209-3224. 